\title{
Reação de Genótipos de Phaseolus vulgaris à Podridão do Colo e ao Oídio
}

\author{
Luiz E. B. Blum ${ }^{1}$, Cassandro V. T. Amarante ${ }^{2}$, Cristiano J. Arioli ${ }^{2}$, Letícia S. Guimarães ${ }^{2}$, \\ Alexandre Dezanet ${ }^{2}$, Pedro Hack Neto ${ }^{2} \&$ Fábio R. Scheidt ${ }^{2}$
}

${ }^{1}$ Departamento de Fitopatologia, Universidade de Brasília, CEP 70910-900, Brasília, DF, e-mail: luizblum@unb.br; ${ }^{2}$ Departamento de Fitotecnia, Centro de Ciências Agroveterinárias,

Universidade do Estado de Santa Catarina, Cx. Postal 281, CEP 88502-970, Lages, SC

(Aceito para publicação em 22/10/2002)

Autor para correspondência: Luiz E. Blum

BLUM, L.E.B., AMARANTE, C.V.T., ARIOLI, C.J., GUIMARÃES, L.S., DEZANET, A., HACK NETO, P. \& SCHEIDT, F.R. Reação de genótipos de Phaseolus vulgaris à podridão do colo e ao oídio. Fitopatologia Brasileira 28:096-100. 2003.

\section{RESUMO}

A podridão do colo (Sclerotium rolfsii) e o oídio (Erysiphe polygoni) são de constante ocorrência na cultura do feijoeiro (Phaseolus vulgaris) no estado de Santa Catarina. O uso de genótipos com resistência genética é uma das alternativas de manejo destas doenças. Avaliou-se a reação a podridão e ao oídio em 80 e 75 genótipos de feijão respectivamente. Os testes foram conduzidos em casa de vegetação em um delineamento em blocos ao acaso. Para os testes com a podridão do colo, cada semente dos genótipos foi inoculada com dois esclerócios de S. rolfsii. A infecção por oídio ocorreu naturalmente. Usou-se a cv. Rio Tibagi como padrão de média resistência à podridão ou de média susceptibilidade ao oídio.
Os genótipos menos afetados pela podridão do colo e que diferiram da 'Rio Tibagi' foram: grupo preto - LA 95105428, FT 646 e Acesso 57; grupo colorido - BAF 50. A maioria dos genótipos não diferiu da 'Rio Tibagi', porém o mais afetado pela podridão do colo foi o BAF 10. Os genótipos mais susceptíveis ao oídio foram o Acesso 57 (Preto) e o FGP CF 101 (Preto). Os genótipos menos afetados pelo oídio foram: grupo preto - Acessos 60 e 36, FGP CF 058, TB 95-03, LM95103904 e LP 96-58; grupo colorido - Akitã, LP 94-1 e LP 96-162.

Palavras-chave adicionais: Sclerotium rolfsii, Erysiphe polygoni e feijão.

\begin{abstract}
Reaction of Phaseolus vulgaris genotypes to stem rot and powdery mildew

The stem rot (Sclerotium rolfsii) and powdery mildew (Erysiphe polygoni) of bean (Phaseolus vulgaris) are common in the State of Santa Catarina, Brazil. The use of less susceptible varieties can reduce the incidence of these diseases. The main goal of this study was to evaluate the reaction of more than 70 bean genotypes (black and colored groups) to stem rot and powdery mildew. The tests were conducted in a greenhouse in a completely randomized block design. Each seed for the stem rot test was inoculated with two sclerotia of $S$. rolfsii. For the powdery mildew tests, the plants were naturally infected by air borne conidia. The

cultivar Rio Tibagi was used as pattern of median resistance towards stem rot and median susceptibility towards powdery mildew for statistical comparisons. The genotypes less affected by stem rot were (compared to 'Rio Tibagi'): black group - LA 95105428, FT 646, and Access 57; colored group ('Carioca') BAF 50. The genotype most affected by stem rot was BAF 10 . Most of the genotypes did not differ from 'Rio Tibagi' in terms of stem rot intensity. The genotypes most susceptible to stem rot were Access 57 (black) and FGP CF 101 (black). The genotypes less affected by powdery mildew were: black group - Access 60, Access 36, FGP CF 058, TB 95-03, LM95103904, and LP 96-58; colored group - Akitã, LP 94-1, and LP 96-162.
\end{abstract}

A podridão do colo causada por Sclerotium rolfsii Sacc. no feijão (Phaseolus vulgaris L.) ocorre em regiões de clima tropical e subtropical, em condições de temperatura e umidade relativa do ar elevadas, seguidas de período seco. O fungo também causa tombamento, podridão radicular e murcha em mais de 500 espécies de plantas (Punja, 1985). Perdas significativas ocorrem em solos infestados pelo patógeno e que apresentam textura leve e umidade próxima à capacidade de campo (Punja, 1985). No sul dos Estados Unidos as perdas podem atingir $5 \%$ da produção anual. No Brasil, desconhecesse a magnitude destas perdas. Os sintomas iniciam-se com lesões marrons e aquosas sobre o colo. As lesões avançam, produzindo escurecimento e podridão do caule, resultando em destruição do córtex e da raiz principal. Conseqüentemente, na parte aérea da planta, isto ocasiona o amarelecimento das folhas inferiores e a seguir das folhas superiores. Plantas severamente afetadas apresentam estrangulamento do colo, o que provoca murcha da parte aérea, seca, queda de folhas e morte da planta (Cardoso, 1994).

Esta podridão é de difícil controle devido à alta capacidade de sobrevivência no solo do patógeno e de sua vasta gama de hospedeiros. Porém, sugerem-se medidas que evitem a introdução de $S$. rolfsii em áreas isentas ou que diminuam a quantidade de inóculo do fungo em áreas já 
infestadas. O uso de material vegetal e sementes sadias, aração profunda, queima ou enterrio profundo no solo dos restos culturais, eliminação de plantas daninhas que sirvam de hospedeiro do fungo, aplicação de calcário, rotação de cultura com plantas tolerantes, como o sorgo [Sorghum bicolor (L.) Moench] e o milho (Zea mays L.), tratamento químico de sementes ou de sulcos e canteiros de plantio em áreas infestadas podem reduzir o problema. $\mathrm{O}$ controle através da utilização de plantas resistentes apresenta grande potencial (Cardoso,1994; Blum et al.,1993; Chaves \& Costa,1999; Blum et al., 2001a).

O oídio causado por Erysiphe polygoni DC. no feijão é de ocorrência mundial, todavia seus danos são variáveis. Podem ocorrer perdas de produtividade entre 17 e $69 \%$ quando a infecção ocorre antes do florescimento (Hall, 1991). Nas folhas desenvolvem-se massas esbranquiçadas de micélio que com o progresso da infecção podem ocasionar amarelecimento e queda de folhas. As hastes e vagens podem ser infetadas. Temperaturas amenas e umidade baixa favorecem a infecção e o surgimento dos sintomas e sinais (Sartorato \& Rava, 1994). Segundo Thakur \& Agrawal (1995), o oídio causado por $E$. polygoni em Vigna radiata (L.) Wilcz. é favorecido em condições de umidade relativa do ar entre 67 e $90 \%$ durante a manhã e entre 12 e $38 \%$ às $12 \mathrm{~h}$. Dentre os principais métodos de controle do oídio citam-se a utilização de cultivares resistentes e a aplicação de fungicidas. Embora o patógeno possua diversas raças fisiológicas, o uso de cultivares com resistência é recomendado (Hall, 1991; Sartorato \& Rava, 1994).

A podridão do colo vem se tornando um problema para as lavouras de feijão na região de Lages e São José do Cerrito,SC (Blum et al., 1993). A variabilidade do agente causal do oídio dificulta os trabalhos de seleção de genótipos de feijão com resistência, porém estudos regionalizados necessitam ser executados. Portanto, desenvolveram-se ensaios em casa de vegetação para avaliar a reação de genótipos de feijão à murcha ou tombamento ocasionado por S. rolfsii e ao oídio.

\section{Testes com Sclerotium rolfsii}

$\mathrm{O}$ isolado do patógeno usado foi obtido de hastes infetadas de feijão (Campos Novos, SC). O fungo foi mantido e multiplicado em BDA (batata, dextrose, ágar). Os genótipos de feijão foram mantidos em sacos de papel sob condições de laboratório $\left(20-22{ }^{\circ} \mathrm{C}\right)$. Os testes foram efetuados entre dezembro e fevereiro de 1999/2000 e 2000/2001, em casa de vegetação $\left(18-30{ }^{\circ} \mathrm{C}\right)$. Devido à similaridade dos resultados, somente os dados de 2000/2001 são aqui apresentados.

Devido a grande quantidade de genótipos e o pequeno espaço disponível em casa de vegetação o experimento foi subdividido em seis etapas quinzenais compostas de 15 genótipos cada. Os genótipos 'Rio Tibagi' e BAF 50 foram testados em todas as etapas, como controle de repetibilidade dos testes. Foram semeadas dez sementes de cada genótipo por repetição, e na superfície da casca de cada uma delas, depositaram-se dois esclerócios do fungo (colônias com 14 dias de idade). A avaliação da doença foi realizada diariamente do $5^{\circ}$ dia após a inoculação até o $14^{\circ}$ dia. São apresentados apenas os resultados do $14^{\circ}$ dia após a inoculação.

Para cada etapa, dois outros lotes iguais de genótipos (mesmo número de tratamentos e repetições) não inoculados com o patógeno foram usados como testemunha. Em um dos lotes as sementes não foram inoculadas com $S$. rolfsii e não foram tratadas com fungicida e no outro lote as sementes não foram inoculadas, mas foram tratadas com benomyl (2 g p.a. / kg de semente). Utilizou-se vasos plásticos pretos $(1,7 \mathrm{~kg}$ de solo), os quais foram preenchidos com solo (cambissolo) esterilizado (1 hora/1 atm/121 ${ }^{\circ} \mathrm{C}$ ), fertilizado com NPK (4$14-8,100 \mathrm{~g} / \mathrm{kg}$ de solo) e com $\mathrm{pH}$ corrigido para 6,5 com calcário dolomítico.

O delineamento experimental do ensaio e suas etapas foi em blocos inteiramente casualizados com cinco repetições (dez sementes/repetição). Foram avaliadas a incidência (\%) e a severidade ( 1 = sadia, 2 = podridão no colo, $3=$ murcha, $4=$ morta e $5=$ não germinada com tombamento em préemergência) de doença em plantas afetadas pelo fungo. A severidade média final de doença foi calculada através da seguinte fórmula: Severidade $=[($ número de plantas na classe 1 de severidade $)+($ número de plantas na classe $2 \times 2)+$ (número de plantas na classe $3 \times 3$ ) + (número de plantas na classe $4 \times 4)+($ número de plantas na classe $5 \times 5$ )]/15. Portanto, os valores finais médios de severidade foram de 0,6 a 3,3 (Blum et al., 2001c).

Como não houve diferença significativa entre os genótipos controle ('Rio Tibagi' e BAF 50) de cada uma das etapas, analisou-se conjuntamente todos os genótipos. Após a coleta dos dados realizou-se a análise de variância e compararam-se as médias de incidência (\%) ou severidade de cada genótipo pelo teste de Tukey (5\%). São apresentadas apenas as comparações entre as médias dos genótipos e a média da cv. 'Rio Tibagi' (Tabela 1).

\section{Testes com Erysiphe polygoni}

Os experimentos foram efetuados entre janeiro e março de 2000 em casa de vegetação $\left(18-30{ }^{\circ} \mathrm{C}\right)$. Foram semeadas dez sementes de cada genótipo por repetição. Sete dias após a germinação das sementes, mantiveram-se quatro plantas por vaso. A infecção dos genótipos ocorreu naturalmente. A avaliação foi realizada aos 60 dias após a semeadura. Foram usados vasos plásticos pretos $(1,7 \mathrm{~kg}$ de solo) com solo (cambissolo) esterilizado ( 1 hora $/ 1 \mathrm{~atm} / 121{ }^{\circ} \mathrm{C}$ ), fertilizado com NPK (4-14-8, 100g/kg de solo) e corrigido (pH 6,5) com calcário dolomítico.

O delineamento experimental foi em blocos inteiramente casualizados com 12 repetições de quatro plantas. Foi avaliada a severidade da doença, pela notação da área foliar coberta pelo fungo, em dois trifolíolos por planta usando-se a seguinte escala diagramática: $0=$ trifolíolo sadio; $1=$ trifolíolo com 0,5 a $2 \%$ de sua área coberta, $2=$ trifolíolo com 3 a 10\% de sua área coberta, $3=$ trifolólo com 11 a $30 \%$ de sua área coberta, e 4 = trifolíolo com mais de $30 \%$ de área 


\section{L.E. Blum et al.}

TABELA 1 - Severidade (S) e incidência (I) da podridão do colo causada por Sclerotium rofsii em feijão (Phaseulus vulgaris), 14 dias após a inoculação

\begin{tabular}{|c|c|c|c|c|c|c|c|}
\hline Genótipo & Grupo & $\mathbf{S}$ & I \% & Genótipo & Grupo & $\mathbf{S}$ & I \% \\
\hline BAF 10 & Colorido & $2,44 *$ & $94 *$ & LM95102581 & Colorido & 1,44 & 48 \\
\hline LA 95105461 & Preto & 1,95 & 72 & LP 96-69 & Preto & 1,43 & 46 \\
\hline Acesso 36 & Preto & 1,93 & $78 *$ & LM95101945 & Colorido & 1,39 & 46 \\
\hline FT 91-4434 & Colorido & 1,92 & 68 & LA 95105447 & Preto & 1,35 & 36 \\
\hline RTU & Preto & 1,92 & 68 & LP 96-48 & Preto & 1,33 & 48 \\
\hline LP 96-302 & Colorido & 1,88 & 66 & LM95102032 & Colorido & 1,33 & 44 \\
\hline LP 96-32 & Colorido & 1,85 & 70 & CI 967/2V & Preto & 1,33 & 42 \\
\hline LP 96-29 & Colorido & 1,85 & 68 & LP 96-58 & Preto & 1,32 & 46 \\
\hline LP 96-23 & Colorido & 1,85 & 64 & Akitã & Colorido & 1,32 & 44 \\
\hline IAPAR 31 & Colorido & 1,84 & $74 *$ & Pérola & Colorido & 1,31 & 40 \\
\hline Acesso 13 & Preto & 1,83 & 60 & LM95103381 & Colorido & 1,29 & 44 \\
\hline LM95103789 & Preto & 1,78 & 64 & FT 91-08 & Colorido & 1,28 & 44 \\
\hline Acesso 60 & Preto & 1,77 & 58 & LM95105034 & Preto & 1,27 & 44 \\
\hline Acesso 07 & Preto & 1,76 & 66 & FGP CF 058 & Preto & 1,27 & 44 \\
\hline PL 95-50 & Preto & 1,73 & 68 & LP 96-37 & Colorido & 1,25 & 46 \\
\hline LA 95105472 & Preto & 1,71 & 62 & FT 740 & Colorido & 1,23 & 44 \\
\hline LP 96-73 & Preto & 1,71 & 60 & BAF 50 & Colorido & 1,20 & 46 \\
\hline LP 96-162 & Colorido & 1,69 & 64 & LP 95-105 & Colorido & 1,20 & 40 \\
\hline LP 94-1 & Colorido & 1,68 & 56 & FT 91-2933 & Preto & 1,19 & 38 \\
\hline FT 625 & Colorido & 1,67 & 64 & LM95103856 & Preto & 1,17 & 48 \\
\hline FT 91-4044 & Colorido & 1,67 & 54 & Aruã & Colorido & 1,16 & 34 \\
\hline FT 91-3920 & Preto & 1,65 & 62 & TВ 95-01 & Preto & 1,16 & 42 \\
\hline LM95103067 & Colorido & 1,65 & 60 & FGP CF 037 & Preto & 1,15 & 42 \\
\hline FGP CF 101 & Preto & 1,65 & 58 & CI 9680 & Colorido & 1,12 & 40 \\
\hline LM95102682 & Colorido & 1,64 & 66 & ТВ 95-08 & Preto & 1,12 & 38 \\
\hline LP 96-41 & Preto & 1,63 & 56 & LP 94-29 & Colorido & 1,11 & 40 \\
\hline LP 96-72 & Preto & 1,56 & 56 & LP 96-63 & Preto & 1,05 & 36 \\
\hline LP 96-372 & Colorido & 1,55 & 58 & LA95105436 & Preto & 1,04 & 38 \\
\hline LM95102789 & Colorido & 1,52 & 64 & AN 730116 & Preto & 1,04 & 30 \\
\hline LP 96-172 & Colorido & 1,51 & 60 & LM95102728 & Colorido & 1,03 & 26 \\
\hline LP 96-70 & Preto & 1,51 & 46 & IAPAR 44 & Preto & 1,01 & 36 \\
\hline ТВ 95-03 & Preto & 1,49 & 58 & Serrano & Preto & 1,01 & 28 \\
\hline MA 733327 & Preto & 1,49 & 52 & Acesso 46 & Preto & 1,01 & 26 \\
\hline LM95103904 & Preto & 1,49 & 48 & Caruru & Preto & 1,01 & $22 *$ \\
\hline FT 91-58 & Preto & 1,48 & 52 & A 785 & Preto & 1,00 & 32 \\
\hline FT Nobre & Preto & 1,48 & 50 & LM95102803 & Colorido & 1,00 & $22 *$ \\
\hline LP 96-46 & Preto & 1,47 & 52 & LM95102835 & Colorido & 0,97 & 28 \\
\hline Rio Tibagi & Preto & 1,47 & 48 & FT 646 & Preto & $0,89 *$ & 30 \\
\hline LP 96-25 & Colorido & 1,45 & 50 & Acesso 57 & Preto & $0,81 *$ & 24 \\
\hline Acesso 55 & Preto & 1,44 & 58 & LA95105428 & Preto & $0,77^{*}$ & $12 *$ \\
\hline
\end{tabular}

C.V. $($ severidade $)=20,9 \%$; C.V. (incidência) $=27,4 \%$; Médias com asterisco $(*)$ diferem da média da cv. Rio Tibagi (Tukey, 5\%).

coberta (Blum et al., 2001b).

Após a coleta dos dados efetuou-se a análise de variância e comparou-se as médias de severidade de doença de cada genótipo com a cv. Rio Tibagi pelo teste de Tukey (5\%). Os dados não sofreram transformações prévias à análise de variância.

Doenças provocadas por $S$. rolfsii são de difícil controle. A seleção de genótipos de feijão com resistência a este patógeno é uma das alternativas de controle, porém pouco explorada. Os testes iniciais para este fim devem ser executados sob condições menos variáveis possível. Neste estudo procurou-se, através de técnicas previamente determinadas (Blum et al., 1993; Chaves \& Costa, 1999), avaliar o comportamento de diversos genótipos (linhagens e cultivares) de feijão em relação à doença causada por $S$. rolfsii.

Verificou-se que o genótipo BAF 10 (Tipo colorido/
Carioca) foi o mais susceptível (Tabela 1) à podridão do colo ocasionada por $S$. rolfsii, quando comparado ao 'Rio Tibagi', padrão de média susceptibilidade ou média resistência (Blum et al., 1993). O genótipo BAF 10 apresentou, no experimento de 2000/2001, os mais altos valores médios de incidência e de severidade. Todavia, as médias de severidade e de incidência no genótipo LA95105428 (Tipo Preto) foram significativamente inferiores às do 'Rio Tibagi'. Cerca de $93 \%$ e $97 \%$ dos genótipos do tipo preto e colorido, respectivamente, não diferiram quanto à severidade de doença em relação a cv. Rio Tibagi.

Notou-se que o acesso da cv. Rio Tibagi usado no presente experimento não apresentou o mesmo grau de resistência relatado em trabalhos anteriores (Blum et al., 1993; Vieira, 1988). A diferença nos resultados de incidência e de severidade de doença, pode estar associada à variabilidade 
genética de acessos da cv. Rio Tibagi e do isolado do patógeno usados nos experimentos.

Os genótipos IAPAR 44 e 31 não diferiam da cv. Rio Tibagi quanto à incidência e severidade de podridão do colo, confirmando os resultados obtidos por Blum et al. (1993). Porém, a cv. Serrano, relatada como susceptível por Blum et al. (1993), não diferiu da cv. Rio Tibagi.

Pelos resultados apresentados nos testes com $E$. polygoni, a maioria dos genótipos testados comportou-se de medianamente susceptível a susceptível ao oídio (Tabela 2). Porém, houve genótipos que foram significativamente mais afetados pelo oídio, quando suas médias de severidade foram comparadas à da cv. Rio Tibagi. Os genótipos mais susceptíveis foram o Acesso 57 (Preto) e o FGP CF 101 (Preto). Os genótipos menos susceptíveis foram os Acessos 60 (Preto) e 36 (Preto), Akitã (Colorido), LM95103904 (Preto), LP 94-
1 (Colorido), LP 96-162 (Colorido), FGP CF 058 (Preto), TB 95-03 (Preto) e LP 96-58 (Preto).

Cerca de $67 \%$ dos genótipos coloridos e de $60 \%$ dos genótipos pretos foram menos afetados pelo oídio do que a cv. Rio Tibagi. Todavia, entre os genótipos que significativamente não diferiram da 'Rio Tibagi', cerca de $83 \%$ eram do tipo preto e $91 \%$, do tipo colorido. Dos genótipos que foram significativamente menos afetados pelo oídio em relação à 'Rio Tibagi', ao redor de $14 \%$ eram pretos e $9 \%$ eram coloridos. Portanto, o presente estudo não mostrou uma diferença marcante quanto à susceptibilidade ao oídio entre feijões pretos e coloridos. Estes resultados contrastam com dados publicados previamente, que mostram uma menor severidade de oídio em genótipos do grupo colorido do que em genótipos do grupo preto (FT-Pesquisas e Sementes, 1986).

TABELA 2 - Severidade (S) do oídio causado por Erysiphe polygoni em feijão (Phaseolus vulgaris), 60 dias após a semeadura

\begin{tabular}{|c|c|c|c|c|c|}
\hline Genótipo & Grupo & $\overline{S^{1}}$ & Genótipo & Grupo & $\mathbf{S}$ \\
\hline Acesso 57 & Preto & $2,676^{*}$ & LM95101945 & Colorido & 1,370 \\
\hline FGP CF 101 & Preto & $2,280^{*}$ & LP 95-105 & Colorido & 1,368 \\
\hline Acesso 7 & Preto & 2,172 & LM95103856 & Preto & 1,335 \\
\hline Acesso 46 & Preto & 2,003 & LP 96-72 & Preto & 1,334 \\
\hline MA 733327 & Preto & 1,986 & LM95103381 & Colorido & 1,301 \\
\hline IAPAR 31 & Colorido & 1,893 & LP 96-46 & Preto & 1,295 \\
\hline CI 967/2V & Preto & 1,883 & LP 96-48 & Preto & 1,290 \\
\hline FT 646 & Preto & 1,872 & LM95102803 & Colorido & 1,281 \\
\hline LP 96-372 & Colorido & 1,845 & Aruã & Colorido & 1,264 \\
\hline LP 96-23 & Colorido & 1,818 & FT 91-08 & Colorido & 1,236 \\
\hline LM95105034 & Preto & 1,775 & LP 96-70 & Preto & 1,235 \\
\hline LA95105428 & Preto & 1,775 & TВ 95-01 & Preto & 1,209 \\
\hline Acesso 13 & Preto & 1,749 & LM95102728 & Colorido & 1,190 \\
\hline IAPAR 44 & Preto & 1,748 & LP 96-32 & Colorido & 1,166 \\
\hline FGP CF 037 & Preto & 1,673 & FT 91-4044 & Colorido & 1,157 \\
\hline CI 9680 & Colorido & 1,643 & LP 96-73 & Preto & 1,138 \\
\hline FT 91-58 & Preto & 1,639 & LM95102682 & Colorido & 1,137 \\
\hline FT 91-3920 & Preto & 1,631 & A 785 & Preto & 1,111 \\
\hline LM95102835 & Colorido & 1,629 & LA95105447 & Preto & 1,077 \\
\hline LP 96-69 & Preto & 1,622 & LM95103786 & Preto & 1,042 \\
\hline LM95103067 & Colorido & 1,600 & LP 96-45 & Preto & 0,953 \\
\hline LP 94-29 & Colorido & 1,584 & FT 625 & Colorido & 0,902 \\
\hline FT 91-4434 & Colorido & 1,578 & Acesso 55 & Preto & 0,879 \\
\hline LM95102789 & Colorido & 1,568 & ТВ 95-08 & Preto & 0,847 \\
\hline LM95102032 & Colorido & 1,565 & FT 740 & Colorido & 0,822 \\
\hline LA95105436 & Preto & 1,561 & LA95105461 & Preto & 0,820 \\
\hline LP 96-29 & Colorido & 1,538 & LP 96-172 & Colorido & 0,744 \\
\hline LP 96-63 & Preto & 1,524 & LA95105472 & Preto & 0,685 \\
\hline Rio Tibagi & Preto & 1,494 & Acesso 60 & Preto & $0,595 *$ \\
\hline Pérola & Colorido & 1,487 & Akitã & Colorido & $0,578 *$ \\
\hline LM95102581 & Colorido & 1,482 & LM95103904 & Preto & $0,468 *$ \\
\hline LP 96-25 & Colorido & 1,466 & LP 94-1 & Colorido & $0,428 *$ \\
\hline AN 730116 & Preto & 1,430 & LP 96-162 & Colorido & $0,410 *$ \\
\hline PL 95-50 & Preto & 1,406 & FGP CF 058 & Preto & $0,380 *$ \\
\hline LP 96-302 & Colorido & 1,405 & Acesso 36 & Preto & $0,313 *$ \\
\hline LP 96-37 & Colorido & 1,400 & ТВ 95-03 & Preto & $0,256^{*}$ \\
\hline FT 91-2933 & Preto & 1,395 & LP 96-58 & Preto & $0,129 *$ \\
\hline FT Nobre & Preto & 1,379 & & & \\
\hline
\end{tabular}

C.V. $=34,5 \%$.

${ }^{1} \mathrm{~S}=$ severidade média de doença (dois experimentos). Médias com asterisco (*) diferem da média da cv. Rio Tibagi (Tukey, $5 \%$ ). 


\section{L.E. Blum et al.}

\section{REFERÊNCIAS BIBLIOGRAFICAS}

BLUM, L.E.B., AMARANTE, C.V.T., MEDEIROS, E.A.A., PRADA, A., GUIMARÃES, L.S. Avaliação da reação de algumas cultivares de feijão a Sclerotium rolfsii. Anais, III Reunião Técnica Catarinense de Milho e Feijão. Chapecó, EPAGRI, 2001a. pp.99103.

BLUM, L.E.B., ARIOLI, C.J., GUIMARÃES, L.S., PRADO, G. Oídio (Erysiphe polygoni) do feijão: comportamento de genótipos em casa de vegetação. Anais, III Reunião Técnica Catarinense de Milho e Feijão. Chapecó, EPAGRI, 2001b, pp.113-116.

BLUM, L.E.B., SCHEIDT, F.R., GUIMARÃES, L.S., DEZANET, A., HACK NETO, P. Reação de genótipos de feijão em relação à podridão do colo (Sclerotium rolfsii), em casa de vegetação. Anais, III Reunião Técnica Catarinense de Milho e Feijão. Chapecó, EPAGRI, 2001c, pp.109-112.

BLUM, L.E.B., MACAGNAN, I., FRISHENK,C. Reação de cultivares de feijão a Sclerotium rolfsii. Fitopatologia Brasileira 18:306-307. 1993.

CARDOSO, J.E. Podridão do colo. In: Sartorato, A. \& Rava, C.A. (Eds.). Principais doenças do feijoeiro comum e seu controle.
Brasília: Embrapa -Arroz e Feijão. 1994. p. 165-173.

CHAVES, K.C. \& COSTA, J.L.S. Influência do método de inoculação e da quatidade de inóculo de Sclerotium rolfsii na severidade de podridão do colo do feijoeiro. Summa Phytopathologica 25:298-302. 1999.

FT-PESQUISA E SEMENTES. Relatório técnico. Ponta Grossa: FT-Pesquisa e Sementes, 1986.

HALL, R. Compendium of bean diseases. St. Paul: American Phytopathological Society Press. 1991.

PUNJA, Z.K. The biology, ecology and control of Sclerotium rolfsii. Annual Review of Phytopathology, 23:97-127. 1985.

SARTORATO, A., RAVA, C.A. Oídio ou míldio pulverulento. In: Sartorato, A. \& Rava, C.A. (Eds.). Principais doenças do feijoeiro comum e seu controle. Brasília: Embrapa -Arroz e Feijão. 1994. pp.103-109.

THAKUR, M.P., AGRAWAL, K.C. Epidemiologic studies on powdery mildew of mungbean and urdbean. International Journal of Pest Management 41:146-153. 1995.

VIEIRA, C. Doenças e pragas do feijoeiro. Viçosa, UFV. 1988. 